Trends Pharmacol Sci. 2013 November ; 34(11): . doi:10.1016/j.tips.2013.09.002.

\title{
How to fix a broken clock
}

\author{
Analyne M. Schroeder and Christopher S. Colwell \\ Laboratory of Circadian and Sleep Medicine, Department of Psychiatry and Biobehavioral \\ Sciences, University of California Los Angeles, Los Angeles, CA 90024, United States
}

\begin{abstract}
Fortunate are those who rise out of bed to greet the morning light well rested with the energy and enthusiasm to drive a productive day. Others however, depend on hypnotics for sleep and require stimulants to awaken lethargic bodies. Sleep/wake disruption is a common occurrence in healthy individuals throughout their lifespan and is also a comorbid condition to many diseases (neurodegenerative) and psychiatric disorders (depression and bipolar). There is growing concern that chronic disruption of the sleep/wake cycle contributes to more serious conditions including diabetes (type 2), cardiovascular disease and cancer. A poorly functioning circadian system resulting in misalignments in the timing of clocks throughout the body may be at the root of the problem for many people. In this article, we discuss environmental (light therapy) and lifestyle changes (scheduled meals, exercise and sleep) as interventions to help fix a broken clock. We also discuss the challenges and potential for future development of pharmacological treatments to manipulate this key biological system.
\end{abstract}

\section{Keywords}

Circadian; chrono-pharmacology; clock; melatonin; SCN; sleep

\section{The Circadian System}

The function of almost every cell in the body is temporally regulated by a molecular feedback loop (Figure 1) composed of a positive and negative arm [1]. The transcription factors Bmall and Clock make up the positive arm and bind to E-box sites driving the expression of inhibitory genes of the negative arm (Per and Cry). PER and CRY proteins negatively feedback to block BMAL1and CLOCK binding to DNA, eventually leading to reduced PER and CRY levels, allowing BMAL1 and CLOCK to restart transcription of Per and Cry. Post-translational modification of these core clock genes along with the presence of modulatory proteins, such as REV-ERBsand ROR $a$, establish a feedback loop with a period of approximately $24 \mathrm{hrs}$. In addition to their role as core clock components, these transcription factors modulate the expression of output genes (clock controlled genes, CCG) that play crucial rate-limiting steps in biochemical reactions, thereby producing $24 \mathrm{hr}$ rhythms in processes such as kinase activity, ATP production, cell signaling, and electrical activity $[2,3]$.

(C) 2013 Elsevier Ltd. All rights reserved.

Contact Information: Dr. C.S. Colwell, Department of Psychiatry and Biobehavioral Sciences, Semel Institute for Neuroscience, University of California Los Angeles, 760 Westwood Plaza, Los Angeles, CA 90024, United States. Tel.: +1 310 206-3973; ccolwell@mednet.ucla.edu.

Publisher's Disclaimer: This is a PDF file of an unedited manuscript that has been accepted for publication. As a service to our customers we are providing this early version of the manuscript. The manuscript will undergo copyediting, typesetting, and review of the resulting proof before it is published in its final citable form. Please note that during the production process errors may be discovered which could affect the content, and all legal disclaimers that apply to the journal pertain. 
This transcriptional/translational feedback loop regulates gene expression throughout the body and microarray studies suggest that approximately 10-15\% of genes display circadian rhythms in expression. Each of the major organ system (heart, liver, pancreas) apparently having its own clockwork to regulate the transcription of genes that are important to the specific target organ [4-7]. Analysis of the rhythmic gene networks suggests that some like "metabolism" are broadly regulated by the circadian clockwork throughout the body. Other regulated networks are tissue specific and important to specific target organs. For example, the networks involved in amino acid metabolism were rhythmic specifically in the liver, while the genes involved in G-protein coupled receptor signaling cascades were selectively rhythmic in heart tissue [4]. These rhythms in gene expression have important implications for pharmacological interventions. For example, knowing that the production of cholesterol in the liver is rhythmic due to circadian regulation of HMG-CoA reductase, it is possible to more effectively reduce cholesterol levels by timing the administration of inhibitors to this enzyme (statins) [8]. The impact of circadian rhythms in gene expression on the pharmacokinetics and pharmacodynamics of drug responses has been recently reviewed [9].

Although cells in most tissues possess a molecular clock, only one nucleus in the brain, called the suprachiasmatic nucleus (SCN) can generate and sustain gene expression and physiological rhythms without any external influence and is therefore recognized as the master clock. The SCN itself is composed of approximately 10,000 neurons with individual neurons exhibiting robust daily rhythms in gene expression, cellular signaling and firing rate activity. The circuit properties and neuropeptide signaling are factors that enable the SCN to generate self-sustaining rhythms [10]. When cultured, SCN explants continue to display rhythms in clock gene expression for many months, while rhythms from cultures of peripheral tissues are shorter-lived [11,12]. Reinstatement or the modulation of rhythms in peripheral tissues can be achieved by refreshing the culture media or applying drugs such as cAMP agonists, catecholamines or glucocorticoids [13-15].

The SCN realigns itself daily to the presence of light and orchestrates the timing of molecular and cellular processes, maintaining proper temporal alignment of function between various tissues [16,17]. In addition to light, behaviors such as feeding and activity are able to feedback and modulate the circadian system [18]. The ability of the SCN to communicate and coordinate the function of tissues such as the heart, lungs, muscle, stomach, liver and brain, allows the body to meet the demands of increased activity and attention during the day and ensure regenerative sleep at night $[19,20]$. Circadian disruption often leads to misalignments in timing among the various systems of the body, therefore components necessary for normal function may be lacking or absent at the desired time of day, which would alter the rhythmic output of behaviors such as wakefulness and sleep. Long-term circadian disruption has been linked to increased incidence of disease such as cancer, cardiovascular disease and diabetes [21-24]. Interestingly, at least in research models, the misalignment of clocks throughout the body appears to be more disruptive than the loss of rhythms [25-27].

\section{Dysfunction and Disease}

Because the circadian system regulates so many aspects of our biology, it is perhaps not surprising that circadian and sleep disorders can be caused by multiple factors Sleep and circadian disruptions are a. sensitive, but perhaps not a very specific, indicator of poor health. Still many of the sleep problems experienced by people are the direct result of poor "circadian hygiene." A convincing argument can be made that as the cost of artificial lighting has come down, the prevalence of sleep and circadian problems increases [28]. The circadian system is very sensitive to blue light exposure (see below) and many people for recreation or work are exposed to this type of light during the night. Light at night alters the 
rhythms of circulating factors, such as melatonin and cortisol that mediate circadian information to various tissues [29,30]. Sleep patterns are also disrupted with light exposure at night [31,32]. Behavioral factors like the timing of feeding and activity modulate the circadian system and eating at the wrong time of day seems to have detrimental effects on the body. Individuals who tend to eat late at night have an increased risk of developing type-2 diabetes and obesity [33]. Shift-work is a prime example of circadian disruption, altering the timing of light exposure, meals and activity, which significantly increases the risk of disease [34-36]. In some ways, the shift-workers serve as early indicators or "canaries in the coal mine" of the long-term consequences of the circadian disruption experienced by a much broader segment of the population. The effects of improper scheduled light and behaviors have also been described and further explored in rodents. The rhythms of melatonin and cortisol are dampened following light exposure at night [37-39] and alters the timing and rhythms of clock and clock controlled genes throughout the body, including in the SCN [40-42]. Long-term exposures to irregular light/dark (LD) cycles or shift work paradigms alter immune function, disrupt reproduction, induce depression and increase the incidence of obesity, cardiovascular disease and cancer [43-51]. Feeding at the wrong time of day induces metabolic changes and disease by decoupling and misaligning the timing of gene expression rhythms of the liver and SCN [52,53].

As the population ages, we can expect to see more problems with sleep and the circadian system. Depending on the survey, sleep disruptions are experienced by about $40-70 \%$ of aged individuals [54]. Aging is a process that progressively weakens the circadian system, leading to a blunted and fragmented daily rhythm in activity, sleep and other physiological processes that is often advanced in phase, including melatonin production, circulating cortisol levels and body temperature [55-59]. Interestingly, a recent study found that PER2 rhythms did not change with age in cultured fibroblasts [60]. However, when serum collected from aged individuals were added to either the aged or young fibroblasts, the period of PER2 rhythms was significantly shortened. The study suggests that changes in some yet unknown circulating factor/s contribute to improper entrainment of peripheral tissues and possibly tissue alignment in aging while the molecular clockwork is intact. Recent studies in rodents also point to aberrant circadian coordination with aging. Despite preserved day/night levels of clock genes in aged mice [61,62], the levels of hormone and neuropeptides in the SCN are reduced $[63,64]$ and the ability of the SCN to produce high levels of neuronal activity during the day is diminished [61]. This decreased output from the SCN is hypothesized to impede its ability to deliver coordinated cues to the peripheral tissues and drive the timing of gene expression in the body, as measured in some tissues of aged animals [61,65]. Aging slows the circadian clocks response to new LD cycles [66] and may also lead to an increased vulnerability to circadian disruption. To provide an example, while young mice can handle a weekly 6 hour advance in their LD cycle, older mice are killed by the same protocol $[67,68]$. While we do not yet know the underlying mechanism, this increase in mortality does provide a dramatic example of the cost of circadian misalignment.

Disruptions in the timing and quality of sleep are common in neurodegenerative disorders such as Huntington's (HD), Parkinson's Disease (PD) and Alzheimer's (AD) [24,69,70]. While it is beyond the scope of this article to discuss this literature, it is worth pointing out that altered timing of gene expression (including clock genes) have been described in each of these diseases [71], suggesting a loss of circadian coordination and possible misalignment. Furthermore, the sleep and circadian disruptions occur early in the disease progression and may even serve as biomarkers for the symptoms that follow [72-74]. One study suggested that the sleep fragmentation seen in $\mathrm{AD}$ patients was specifically correlated with the loss of vasopressin expressing cells in the SCN [75]. Finally, since circadian and sleep disruptions alone increase oxidative stress and inflammation [76-78], it is quite 
possible that the circadian and sleep disruptions experienced by the patient for many years could accelerate the pathology throughout the nervous system [79]. Therefore, targeting and strengthening circadian function may prove beneficial for other symptoms of the disease. Mouse models of these diseases indicate that the circadian system is impacted [80-85] and are helping uncover the cause of disruption.

Because circadian disruption can be detrimental to daily lives of the patients and care givers, effective interventions are needed in order to re-establish alignment to produce a more robust circadian system. Current strategies include the use of stimulants and sleep aids to combat increased sleepiness and sleeplessness, but these treatments target symptoms and may have no or minimal benefits for the circadian system. Stimulants such as modafinil, amphetamines, nicotine and caffeine, may contribute to the problem with their disruptive effects on sleep [86] and can be addictive with side effects. Most prescription sleep aids such as barbiturates, benzodiazepines and zolpidem enhance GABA signaling, activating sleep centers (e.g. ventrolateral preoptic nucleus, VLPO) that induce sedation, but may not restore the normal restorative stages of sleep [87]. GABA is also the principal neurotransmitter in the SCN and alterations in GABA signaling can disrupt the central clock [88]. The best-studied drug for circadian modulation is melatonin (see melatonin section below) but still, more work will have to determine the circadian consequences of all these current treatment options. Pharmacological fixes are few, but there is growing interest in the development of novel drugs that target circadian mechanisms with the goal of alleviating conditions resulting from circadian disruption. In the remainder of this article, we discuss circadian targeted interventions that may be helpful in realigning and reinstating circadian rhythms, including environmental and lifestyle changes. Possible opportunities to develop effective drug treatments will be discussed. What is clear is that interventions to strengthen the circadian system are required to treat the growing number of individuals who experience frequent circadian disruptions. Fixing a broken clock would not only be a means of improving the quality of daily lives by reestablishing proper sleep/wake behavior, but also a step in preventing the development of more serious diseases as we age.

\section{Fixing a broken clock}

\section{Light therapy}

The modern world has given us the power to control light, either by switching on the light at night to finish reading this article or by retreating indoors during the day to escape the heat or maybe to watch a movie in the theaters. By removing ourselves from natural lighting, we may be exposing ourselves to new risks. For example, the rise in Vitamin D deficiency appears to be the direct result of insufficient exposure to sunlight [89]. As described above, improperly timed light exposures can lead to circadian disruptions and disease. Knowing this, it makes sense that taking control of light and establishing greater variance of light intensities between night and day may be crucial for good health and a tool to help reinstate a more robust circadian system.

Light is the most potent environmental cue for the circadian system and can predictably phase shift the timing of behavior [90]. The light signal is detected by specialized intrinsically photosensitive retinal ganglion cells (ipRGCs) containing melanopsin [91-93]. This photopigment is sensitive to shorter blue/green wavelengths while relatively insensitive to the red shifted lighting. Aberrant light exposure directly alters circadian properties by inducing immediate molecular and cellular changes within the SCN, including increases in $c$-fos and Perl transcription, and increases in firing rate of SCN neurons. These changes shift the timing of the molecular clock within SCN neurons and throughout the body [9499]. In diurnal animals, exposure to even low intensities of blue light during the night acutely interferes with sleep by inhibiting sleep-promoting neurons, acutely reducing 
melatonin levels, activating arousal-promoting orexin neurons and stimulate the sympathetic axis [100-102]. These effects lead to poor sleep quality as well as reduced daytime alertness the following day. Long-term exposures to aberrant light cycles increase the risk for disease. A broken circadian system may benefit from exposure to robust and regular LD cycles to help reinforce temporal patterning of SCN properties that allows for defined entrainment to the external environment and better control of tissue function. This realignment of the circadian network will likely improve restorative sleep as well as daytime alertness.

The idea of reinforcing the circadian system using light has been in regular practice for some conditions such as advanced/delayed sleep phase syndrome, jetlag, shift work, seasonal affective disorder and depression, which include circadian disruption in their list of symptoms $[103,104]$. Light therapy in these conditions help improve mood and re-establish the daily sleep/wake cycle [104-106]. The use of light therapy is now being extended to other conditions with circadian symptoms. In aging, individuals experience improvements in daytime alertness and sleep following light therapy [107-109]. In addition to improvements in sleep, patients with neurodegenerative disorders show improvements in motor and cognitive abilities [110-115]. Patients with major depression, who are resistant to antidepressant medications show amelioration of mood when light therapy is included in the treatment regimen [116]. It is important to mention that other studies have shown no or small changes in objective and subjective measures of sleep as a result of light therapy $[108,117-119]$, which raises questions of study design with the wavelength, intensity, duration of the light as well as the timing of treatment relative to the endogenous circadian rhythm all being critical factors. Ongoing studies should take into account these various factors when exploring the benefits of light intervention and its ability to reinforce circadian function and behavior. But it is worth re-emphasizing that even young, healthy individuals can be influenced by improved light exposure [120]. In one recent study found that just taking young adults outside and exposing them to natural lighting for several days can shift the phasing of their melatonin rhythm by 2 hours [121]. Thus lighting conditions provide one of our most powerful tools to influence the circadian system.

\section{Scheduled Meals}

For most of us, food is now available 24/7 and we can eat any time in the day or night. While this constant availability is convenient, studies suggest that the constant consumption of food or the intake of food at inappropriate times are detrimental feeding habits that lead to imbalanced metabolic function due to disruption of circadian function. The growing incidence of metabolic syndrome is a growing health concern that requires attention and greater understanding.

The circadian system contributes to metabolic homeostasis through the regulation of daily rhythms in physiological processes that include appetite, gastrointestinal function, nutrient absorption, pancreatic insulin secretion and hepatic enzyme activity [122-124]. These functions are coordinated by humoral and neural signals from the SCN that drive and modulate the molecular feedback loop in metabolic tissues, including the liver and pancreas [125-127]. Key rhythmic clock genes in peripheral tissues, such as Bmall and Clock, and the nuclear hormone receptors Rev-erb a and Rora, have been shown to interact and modulate crucial steps of the metabolic pathways, enabling the circadian system to directly affect metabolism. Disruptions of the circadian system, either through genetic ablation of circadian clock genes (Bmall, Clock) or the use of jetlag protocols lead to the loss of rhythms in clock and metabolic genes in the liver and pancreas, and in many cases depress absolute expression levels of these genes [50,128-131]. Circadian dysfunction often result in pathologies consistent with metabolic syndrome, including hypoinsulinaemia, hyperglycaemia and obesity [130,132-134]. In humans, long-term disruptions in the sleep/ 
wake cycle lead to metabolic disruptions [135,136], but even short durations of circadian misalignment appear to be sufficient to produce pre-diabetic conditions in the body [27].

But it is also clear that components of the metabolic pathway interact with the molecular clock, creating a feedback loop that likely enables the circadian system to sense changes in cellular state and respond accordingly in order to achieve a balance in energy intake and expenditure. The timing, frequency and volume of food intake [137,138], as well as the nutrient composition of food have been shown to alter circadian function [139-141]. Disruptive feeding conditions can result in circadian dysfunction and metabolic imbalances $[142,143]$. For example, in mice and rats, food access restricted during inappropriate times of day (i.e. during the normal sleep phase) shifts the phase of the molecular clock in peripheral tissues including the liver, adrenals and fat cells, but does not alter rhythms in the SCN [52,53]. This results in a misalignment of rhythms between peripheral tissues and the SCN that leads to altered expression of key metabolic enzymes, changes in energy balance and weight gain $[144,145]$. Disruptions in circadian and metabolic function were also found in rodents fed a high fat diet (HFD) provided $a d$ lib. Despite the consumption of the same amount of calories between rodents fed normal chow or a HFD, only the HFD led to changes in behavioral periodicity, disruption of the molecular clock in beta-cells of the pancreas and the liver, alterations in the rhythms of metabolic genes in the liver, impairment of insulin secretion, and increase in weight, which are all signs of metabolic syndrome $[140,141,146]$. However, scheduling HFD access to $8 \mathrm{hrs}$ within the middle of the active period, reverses the effects of ad lib HFD [140,147]. In mice lacking a functional molecular clock (Cryl,2 dKO), scheduled feeding can restore rhythms of most clock and metabolic genes in the liver and prevent weight gain [148]. These studies suggest that metabolic homeostasis is dependent on an intact circadian system and an appropriate time of feeding.

Adherence to a feeding schedule that preserves and reinforces the phase relationships of clock gene expression between the SCN and peripheral tissues may be a lifestyle choice crucial for maintaining good health. In aging and neurodegenerative diseases where SCN communication with peripheral tissues is deficient, scheduled feeding may supply the necessary cues to properly realign molecular rhythms among tissues and with the LD cycle. In mouse models of $\mathrm{HD}$, scheduled feeding appears to be able to entrain the peripheral tissues [83]. In humans, higher measures of daily routine, including meal time, is correlated with higher self-reported sleep quality in a variety of subjects [149-152]. What has to be determined is whether the timing of food consumption within the active period matters. In $\mathrm{AD}$, feeding behavior is altered, whereby the peak of calorie intake is phase advanced. These shifts in timing are correlated with lower body weights and worse cognitive and behavioral symptoms [153], suggesting a relationship between timing of food intake and severity of disease. Studies should examine whether adjustments in meal times may help disease symptoms. Much more work will need to be done to clarify the benefits of scheduled feeding including its potential to realigning the circadian system.

\section{Scheduled Exercise}

Studies suggest that the scheduling of exercise or stimulated activity may be a method to improve the function of the circadian system and strengthen its regulation of peripheral outputs. The temporal patterning of activity is an output regulated by the circadian system, but studies demonstrate that stimulated activity or exercise can also feedback to the circadian system and alter its function. Under constant dark conditions, a single, short bout of stimulated activity in the middle of the subjective day (the time when the animal perceives it is day despite the lack of light cues), causes the circadian system of rodents to phase advance resulting in an earlier onset of wheel running activity the following day, while stimulated activity induced during the end of the subjective night results in phase 
delays $[154,155]$. The rate of re-entrainment following a shifted LD cycle can be accelerated when exercise or wheel availability is aligned to the new lighting schedule, and decelerated when wheel availability is scheduled at inappropriate times [155-157]. Stimulated activity altered SCN properties in rodents and induced direct and immediate changes in clock gene expression and neuronal firing activity [158-160]. The daily scheduling of exercise in WT mice under LD conditions, either during the first or second half of the dark phase differentially shifted the rhythms of behavior and physiology and altered gene expression rhythms in the SCN and peripheral tissues [161].

The circadian system in humans responds to exercise as well. Although the evidence for the effect of a single, short bout of exercise on the circadian system in humans is not as clear as in rodents, exercise appears to be able to delay the timing of circadian system as measured by shifts in the timing of melatonin rhythms [162-165]. These responses are also dependent on the duration and intensity of exercise [166]. Exercise can also speed up re-entrainment of the circadian system [167] and can aid in readjustments of schedule during shift work $[168,169]$. These studies demonstrate effective modulation of the circadian system brought about by exercise in rodents and humans.

Some data suggests that scheduled exercise can be used to help counter the conditions in which the circadian system is compromised. In aged mice, scheduled wheel access boosted the amplitude and improved the temporal patterning of activity and rest when compared to aged animals without wheels [170,171]. Furthermore, the rate of re-entrainment of activity and clock gene expression rhythms following an $8 \mathrm{hr}$ shift in the LD cycle was accelerated with voluntary exercise in aged animals [170]. In mutant mice with a disrupted circadian system (Vip-/-; Vipr2-/-), the scheduling of wheel access for 6 hrs every 24 hrs improved the rhythms of behavior [172] and physiology [161]. Even the rhythms in clock gene expression could be rescued by wheel access at some phases but not others [161]. There is also some evidence in humans that exercise can have beneficial effects on the circadian system. Long-term fitness training in the middle of the day, improved the consolidation of the sleep/wake cycle in older men [173]. Exercise during the afternoon or early evening improved self-reported sleep quality in older adults with insomnia [174]. Similar to studies in rodents, there may also be a specific time where the benefits of exercise are maximized. Although both exercise in the morning and late afternoon improved cognitive abilities in aged individuals, late afternoon exercise improved more measures of cognitive abilities [175]. Unfortunately, in mice or men, the mechanisms mediating exercise's effect on the circadian system are not yet known.

\section{Scheduled Sleep}

The circadian system has reciprocal neural connections to the brain regions that regulate arousal and sleep [176]. Through these connections, the SCN can convey temporal information to the diffuse network of sleep and arousal promoting structures of the brain and body [177,178]. Under normal conditions, peak circadian drive of arousal in humans is thought to occur in the afternoon to counteract the growing fatigue as the homeostatic drive to sleep increases [179]. Interestingly, this communication appears to be bidirectional, as "sleep centers" communicate information related to sleep state back to the SCN as well [180]. Thus, the sleep and circadian control system are closely intertwined and can be difficult to disentangle. Manipulations that interfere with sleep can reduce the amplitude of clock gene expression at least in the periphery [181] and alter electrical activity in the SCN. For example, during slow wave deprivation, $\mathrm{SCN}$ neuronal firing remained high and failed to show the normal nocturnal decrease in firing rate, while during REM sleep deprivation, SCN neuronal firing remained low and failed to display increases in firing [180]. A long line 
of experimental evidence indicates that surgical or genetic manipulations that interfere with the circadian system will alter the timing of sleep $[182,183]$.

This tight reciprocal regulation also provides the opportunity for intervention. It is reasonable to speculate that by imposing a schedule of sleep, we can also improve circadian rhythms. While we are not aware of evidence for this in humans, there is some literature in support of this hypothesis in mice. In a mouse model of HD (R6/2 mouse), both the sleep/ wake cycle and the molecular clock in the SCN are disrupted [184]. The daily administration of alprazolam (a benzodiazepine) induced approximately $4 \mathrm{hrs}$ of sleep during the inactive period in the HD animals. This treatment improved health, cognitive and motor function, and survival. Also, the pharmacological imposition of sleep reshaped gene expression in the SCN with improved expression profiles of the clock gene Per 2 and of the circadian output gene Prok2. In a separate study, pharmacological control of both the sleep and wake cycle using alprazolam and modafinil, respectively, further improved cognitive function, however the effects on the circadian system were not examined [185]. This work is beginning to provide the "proof of concept" that one way to fix a broken clock may be to impose a sleep schedule.

\section{Pharmacological Targeting of the Circadian System}

Behavioral or lifestyle changes as a means of fixing a broken circadian clock are promising interventions aimed to restore and stabilize the circadian system in a LD environment. However, these lifestyle changes may be difficult to impose or ineffective in patients with certain conditions. Future circadian modulating drugs could be designed to achieve various goals (Table 1). First, analogous to the goals of scheduled activities, an ideal class of drugs should enhance the function of the central clock and improve SCN control of peripheral tissues. For example, the neuropeptide VIP is required for synchronous gene expression and firing rate rhythms among the individual neurons of the SCN. Developing agonists for $V i p r 2$, the dominant VIP receptor in the SCN may enhance synchrony and function of the SCN in conditions of aging and neurodegenerative disease shown to result in decreased VIP expression [186,187]. Chronic infusion of a Vipr2 agonist (BAY 55-9837) did alter the circadian cycle length in vivo [188], and further study in circadian compromised animals is warranted. Second, there would also be a need to identify drugs that shift the timing of the internal clock relative to the LD cycle through, for example, alteration in period or phasing of the central clock. Third, drugs that can bypass the central clock and directly drive rhythms of peripheral tissues would be helpful. For example, circulating factors such as melatonin, cortisol and catecholamine can alter the molecular clock of peripheral tissues and phase dependently accelerate or delay realignment to a shifted LD cycle [189-191]. Lastly, to facilitate rapid shifts in the timing of the clock, in anticipation of shift work or jet lag, drugs might be designed to suppress the central clock, which could then be more easily reset when followed by drugs that reestablish a robust rhythm in the new time zones or with altered phase relationship to the LD cycle [192].

\section{Melatonin as a test case}

At present, melatonin and its receptor agonists (ramelteon, agomelatine) have been the most studied class of pharmacological agents targeting the circadian system (Figure 2). Melatonin is a naturally occurring hormone that is rhythmically secreted by the pineal gland, reaching peak plasma levels at night. There are two classes of high affinity G-protein coupled receptors (MT1; MT2) as well as weaker evidence for an intracellular binding domain (MT3) and possible interactions with nuclear receptors [193,194]. The melatonin receptors are widely distributed in the CNS, heart, endocrine and immune system where their activation has been reported to have wide ranging effects. The nightly surge in melatonin levels is regulated by the SCN and likely aids in mediating entrainment of other peripheral 
tissues. We suspect that robust rhythms in melatonin are a crucial factor for normal circadian function and good health. Reduced melatonin signaling caused by polymorphisms in the melatonin receptors or in rate-limiting enzymes involved in the production of melatonin, are linked to increased incidence of disease including diabetes, cardiovascular disease, multiple sclerosis and depression [195-199]. Circadian disruption, caused by long distance travel, shift work or increased light exposure at night, leads to a blunted melatonin rhythm, poor sleep quality and is associated with increased incidence of disease [23]. In female shift workers, for example, lower levels of urinary melatonin was associated with increased risk for breast cancer [200]. Rhythms in melatonin levels are also reduced in aged individuals and those with AD and PD [201], while a delayed peak in melatonin levels was detected in early stage HD [202].

Melatonin supplementation can be used to support the endogenous rhythms of melatonin, shift the phase of the central clock relative to external environment and help realign peripheral tissues. For example, melatonin helped speed up re-entrainment in travelers and reduced jet lag symptoms [203]. In aged individuals with lower amplitude melatonin rhythms, supplementation with melatonin improved sleep, morning alertness, cognitive performance and quality of life in aged individuals $[110,204]$. These same benefits were observed in patients with neurodegenerative disorders [205,206]. Adolescents with delayed circadian rhythms and irregular sleep patterns benefit from melatonin supplementation, which shifted their circadian system to an earlier phase, improved day-time alertness and decreased sleep latency [207]. Melatonin added to beta-blocker ( $\beta$-adrenergic receptor antagonists) therapy for hypertension, counter sleep disruptions that can result from betablocker treatment alone [208,209]. Whether melatonin is effective among shift workers is not yet clear but, benefits are observed in some studies [104,210]. In contrast to other hypnotics, melatonin does not alter sleep architecture and has minimal side effects. Administration of melatonin in the late afternoon or early evening in order to phase advance the circadian system may induced unwanted sleepiness. It is worth noting that agomelatine activates MT1 and MT2 receptors and inhibits 5-HT2C serotonin receptor. This melatonin agonist with its modulatory effects on the circadian system appears to also have beneficial effects on mood and is currently being marketed as a novel antidepressant [211]. One of the striking aspects of the literature with melatonin is the variability in the response from study to study and within individuals. It seems likely that more thought needs to be put into the dosage and timing of melatonin treatments to maximize the therapeutic benefits for the individual patient. It is important to keep in mind that in addition to circadian mechanisms, melatonin has been reported to have direct antioxidant effects [112,212].

\section{Repurposing established drugs}

There are medications currently on the market prescribed for other conditions that could be evaluated for their effects on the circadian system. For example, lithium and valproic acid (VPA) are mood stabilizers traditionally prescribed for individuals with bipolar disorder. Therapeutic effects of lithium may be mediated by its ability to alter the molecular clock through its interactions with glycogen synthase kinase 3 (GSK-3 $\beta$, Figure 3 ) that results in the modulation of rev-erba expression, increase in the amplitude of Per2 and Bmall rhythms and alteration in circadian period of behavior in mice [213-215]. Both lithium and VPA alter the molecular clockwork [213,216]. While lithium's side effects may limit its use, agents that increase the cycle length of the circadian system could be useful in patients with phase-advanced syndrome. Other molecules that target the GSK signaling cascade may have a better safety profile. To provide another example, metformin is a drug prescribed for type-2 diabetes and mediates its effect through the activation of adenosine monophosphateactivated protein kinase (AMPK). Metformin shortens the period of Per2 in rat fibroblasts through the AMPK phosphorylation of casein kinase I $\varepsilon(\mathrm{CKI} \varepsilon)$, a modulator of the 
molecular clock. In mice, a single metformin treatment can phase advance clock gene rhythms in the heart, muscle and fat [217]. Chronic administration of metformin in drinking water resulted in alteration in the rhythms of clock and metabolic genes in a tissue specific manner [218]. Metformin's ability to shorten the circadian cycle makes it an interesting drug to further explore as a treatment for phase delayed syndrome [219]. The positive effects of metformin on the clock was demonstrated in mice fed a HFD, whereby metformin improved AMPK and SIRT1 function and reversed the detrimental effects of HFD on clock genes in white adipose tissues [220].

Finally, it is worth mentioning that serotonergic agents, in addition to mood altering effects, may be a potential class of drugs to modulate the circadian system. Based on a number of animal and drug studies, serotonin has been shown to be involved in photic and nonphotic (activity feedback) entrainment of the circadian system [221]. The SCN expresses multiple serotonin $\mathrm{G}$ protein-coupled receptor subtypes, which are activated by serotonergic input that originates from the medial raphe nucleus of the brainstem [222]. Although the contribution of each receptor subtype in the regulation of the circadian system is still being studied, the manipulation of serotonin signaling using various 5HT agonists and SSRIs, has been shown to phase dependently alter cAMP, ERK and CREB mediated signaling, and potentiate phase shifts of clock gene expression, SCN activity and wheel running behavior in response to light input [223-226]. This amplification of photic response suggests that serotonin could potentially be used to help resynchronize, shift and strengthen circadian function and counter the effects of disruptive external stimuli. In fact, serotonin influence on SCN and photic response may be a mechanism by which SSRIs improve mood in various psychiatric conditions known to interact with the circadian system, including Seasonal Affective Disorders (SAD) [227]. Furthermore, serotonin has also been shown to modulate gsk-3 $\beta$ in flies, which is a proposed circadian target of the mood altering drug lithium described above [228]. Consistent with this idea, the depressive and cognitive deficiencies induced by aberrant light exposures and circadian disruption were reversed by administration of SSRIs [229,230]. The availability of selective serotonin receptor agonists and antagonists (ex. lurasidone, an atypical antipsychotic, 5HT-7 antagonist [231]) and emergence of future drugs will determine whether targeting of serotonin signaling will be useful for circadian modulation.

\section{New drugs}

There are a growing number of new drug targets for circadian modulation being developed in laboratories (Figure 3). An inhibitor of CK1 $\delta$ lengthens the period of the circadian clock at both molecular and behavioral levels [232]. Interestingly, when the CK1 $\delta$ inhibitor was applied to SCN slice preparation from a mouse model of circadian disruption (Vipr2 -/-), PER2 driven bioluminescence rhythms, which are usually damped in amplitude, began to oscillate robustly. The daily administration of the inhibitor in vivo was also able to induce a more robust circadian rhythm in wheel running behavior in Vipr2-/- mice, which normally display poor rhythms under constant conditions. Similar beneficial effects on wheel running behavior were observed in WT animals housed under constant light conditions, which renders most animals arrhythmic. This drug target is promising, as the treatment appears to be able to entrain and strengthen the circadian system despite the aberrant presence of light, which would be highly beneficial for shift-workers. Furthermore, many familial cases of advanced sleep phase syndrome are caused by improper turnover of PER2, and the inhibition of CK1 $\delta$ in these cases may lengthen period and phase delay the circadian system in these individuals [233].

Recent work has also examined the impact of synthetic REV-ERB agonists and found that these compounds can alter the molecular clock both in vitro and in vivo [234-237]. A single 
dose of synthetic REV-ERB ligand applied in constant darkness during the phase at which REV-ERB was expected to be high (CT 6), reduced wheel-running activity for one day. This treatment disrupted the molecular clock in the SCN with a boost in amplitude of Per2 expression and a variety of other changes in the gene expression rhythms. In a LD cycle, the effects of the drug treatment were weaker. The impact of chronic treatment was not examined. In the liver, REV-ERB ligand injection caused a shift in the timing of Per2 expression and a reduction in rev-erba. Consistent with Rev-erb's role in metabolism, the agonist altered the expression of metabolic genes in the liver, skeletal muscle, and white adipose tissue. Long-term administration of the agonist continued to modulate metabolic gene expression in the liver and ultimately resulted in greater weight loss in diet-induced obese mice as well as in leptin-deficient mice. The circadian system also regulates rhythms in immune function, and the REV-ERB ligand was able to modulate the production and release of the proinflammatory cytokine IL-6, supporting its role as a drug for regulation of the immune system [238]. This study demonstrated Rev-erb's role in modulation of the molecular clock and physiological outputs but a causal relationship between these two processes has not yet been established.

Alterations in clock gene expression were also induced by pharmacological activation of a metabolic related gene, Sirtuin1 [239]. Sirtl is a sensor of cellular metabolism and more recently, was shown to directly associate with Clock and Bmall [240]. Rhythms in enzymatic activity of Sirtl suggest regulation by the circadian system, while the resulting disruption of the molecular clock in liver specific Sirt1 knockout mice demonstrates Sirt1 feedback to the molecular clock. This work suggests that Sirtl is a link between the clock and the maintenance of cellular energy state. The upregulation of Sirt 1 expression in mice using synthetic activators for multiple weeks caused a depression in Per2 and Dbp expression in the liver due to alterations in promoter binding of CLOCK and BMAL1 and changes in the levels of histone acetylation. These studies support the idea that manipulation of genes involved in the regulation of metabolism may be potential targets to modulate the molecular clock and circadian behavior. Currently, the Rev-erba and sirtuin1 agonists appear to be disruptors of the molecular clock and could be used to suppress or 'prime' the circadian system, to allow for an incoming circadian signal to quickly re-entrain and shift rhythms throughout the body. The ability of these agonists to improve the molecular clock may depend on timing and dosage of administration as well as specificity in tissue targeting.

Future drug targets can take advantage of the other known inputs or modulatory molecules of the SCN [241], such as Neuropeptide Y (NPY) and Nitric oxide (NO). NPY is thought to communicate nonphotic feedback [242] to the SCN. NPY application can phase dependently shift the timing of firing rate rhythms, clock expression in the SCN and circadian behavior [243-247]. Further development of a drug modulating NPY signaling must take into account this peptide's role in many other physiological processes including feeding, cell proliferation, cancer and cardiovascular disease [248]. Similarly, NO is a component of the signal transduction cascade that mediates light induced phase shifts by phosphorylation of CREB as well as modulation cGMP levels in the SCN $[249,250]$. Sildenafil, or Viagra, activates the cGMP pathway similar to NO, and has been shown to accelerate light induced phase shifts in hamsters. Therefore the use of sildenafil or future drugs targeting this pathway, could be a potential treatment for jetlag and shift work [251]. We suspect that many people may already be taking Sildenafil during their holidays. Of course, the application of drugs targeting either NPY or NO signaling for circadian application will depend upon the identification of receptor subtype specificity or some other means to limit pleitropic effects of these signaling pathways.

Finally, the circadian system controls the timing of arousal through the regulation of the electrical activity in a network of neurotransmitter systems including cell populations 
expressing norepinephrine (locus coeruleus), serotonin (raphe), histamine (tubelomammiary nucleus) and orexin/hypocretin (hypothalamus) [253,254]. Theoretically blocking any of these arousal systems will help induce or maintain sleep and, as described above, a pharmacologically-induced sleep schedule could well drive a circadian cycle. Orexin plays a critical role in promoting arousal and the loss of these neurons is associated with the sleep disorder narcolepsy $[255,256]$. The discovery and characterization of this peptidergic system has created the opportunity for new classes of drugs including hypnotics (orexin receptor antagonists) and stimulants (orexin receptor agonists). A number of these agents are under development with the work on dual orexin 1 and 2 receptor antagonists (DORAs) apparently being the furthest along [257,258]. These compounds are generating a lot of excitement as they raise the possibility of new treatments for sleep and circadian disorders without some of the cognitive impairment observed with GABA-modulators (benzodiazepine-like) which are presently the main treatments for insomnia $[259,260]$. Of course, we do not yet understand the potential side effects of these DORA drugs and whether they offer significant benefits over the "Z-class" drugs (zaleplon, zolpidem, zopiclone, and eszopiclone) that are presently so widely prescribed. Past experience, which has seen us welcome new sleeping aids with great enthusiasm (e.g. chloral hydrate or barbiturates) only to see the negatives appear later with wide-spread use, suggests that we take a cautious approach.

\section{In the pipeline}

High throughput screens are aiding scientists in identifying new targets for the circadian system that would allow measurable temporal control of the molecular clock $[87,252,261,262]$. Changes in the amplitude, period and phase of clock gene rhythms using luciferase-based readouts in cell cultures, are helping to identify promising candidates. The large array of molecules that have so far been identified provides a pool of multiple pathways that interact with the molecular clock [261]. We do not know much about the chemical identity of the clock modulators, but CKI inhibitors were reported to lengthen the cycle length as expected. Particularly intriguing are the class of compounds that were reported to restore the amplitude of damped clocks. With aging and neurodegenerative diseases reducing the amplitude of the circadian oscillations in peripheral tissues, these compounds could provide a useful counter-measure. Of course, these targets will have to be further explored in different tissue types as well as in vivo in order to determine its effects on multi-oscillatory systems and subsequent benefits or consequences on physiology. The multitude of potential chemical substances also presents a challenge in identifying and investing in the most promising targets. As we outline in Table 1, there is not a single drug (a.k.a. the "magic bullet") that will solve all problems with the circadian system.

\section{Concluding remarks}

The circadian timing system regulates the temporal patterning of many physiological and gene expression networks within our body. Disruption of this timing system has a wide ranging impact on our health. Aging as well as neurological and psychiatric disorders challenge the proper functioning of the circadian system and result in a break down in the sleep/wake cycle including trouble sleeping at night as well as daytime fatigue. Even for healthy individuals, modern living creates work schedules that do not fit with our biology resulting in insufficient sleep, inappropriate light exposure and mealtimes; all factors which challenge our circadian system [263]. Defenses against a "broken clock" include adopting a strategy of temporally structured light exposure, meals, and exercise. Pharmacological manipulations will need to be targeted to the specific goal e.g. aligning peripheral organs, enhancing the amplitude of the central clock or even suppressing the central clock during travel or shift work. While melatonin and its agonists have been the most studied, repurposed established drugs have promise and new clock-specific agents are in the pipeline. 


\section{Acknowledgments}

We would like to thank Donna Crandall for technical expertise with figure designs. Work supported by NRSA award F31NS070529 and Neurobiology Training Grant 5T32NS7101-33 from the University of California, Los Angeles to A.M.S., as well as support by the CHDI Foundation, the Oppenheimer Foundation, and the American Heart Association to C.S.C.

\section{References}

1. Ko CH, Takahashi JS. Molecular components of the mammalian circadian clock. Hum Mol Genet. 2006; 15(Spec No 2):R271-277. [PubMed: 16987893]

2. Schibler U. The daily timing of gene expression and physiology in mammals. Dialogues Clin Neurosci. 2007; 9:257-272. [PubMed: 17969863]

3. Reppert SM, Weaver DR. Coordination of circadian timing in mammals. Nature. 2002; 418:935941. [PubMed: 12198538]

4. Storch KF, et al. Extensive and divergent circadian gene expression in liver and heart. Nature. 2002; 417:78-83. [PubMed: 11967526]

5. Akhtar RA, et al. Circadian cycling of the mouse liver transcriptome, as revealed by cDNA microarray, is driven by the suprachiasmatic nucleus. Curr Biol CB. 2002; 12:540-550.

6. Duffield GE, et al. Circadian Programs of Transcriptional Activation, Signaling, and Protein Turnover Revealed by Microarray Analysis of Mammalian Cells. Curr Biol. 2002; 12:551-557. [PubMed: 11937023]

7. McCarthy JJ, et al. Identification of the circadian transcriptome in adult mouse skeletal muscle. Physiol Genomics. 2007; 31:86-95. [PubMed: 17550994]

8. Wuarin J, et al. The role of the transcriptional activator protein DBP in circadian liver gene expression. J Cell Sci Suppl. 1992; 16:123-127. [PubMed: 1297647]

9. Musiek ES, Fitzgerald GA. Molecular clocks in pharmacology. Handb Exp Pharmacol. 201310.1007/978-3-642-25950-0_10

10. Welsh DK, et al. Suprachiasmatic nucleus: cell autonomy and network properties. Annu Rev Physiol. 2010; 72:551-577. [PubMed: 20148688]

11. Yoo SH, et al. PERIOD2::LUCIFERASE real-time reporting of circadian dynamics reveals persistent circadian oscillations in mouse peripheral tissues. Proc Natl Acad Sci U S A. 2004; 101:5339-5346. [PubMed: 14963227]

12. Yamazaki S, et al. Resetting Central and Peripheral Circadian Oscillators in Transgenic Rats. Science. 2000; 288:682-685. [PubMed: 10784453]

13. Balsalobre A, et al. A serum shock induces circadian gene expression in mammalian tissue culture cells. Cell. 1998; 93:929-937. [PubMed: 9635423]

14. O’Neill JS, Reddy AB. The essential role of cAMP/Ca2+ signalling in mammalian circadian timekeeping. Biochem Soc Trans. 2012; 40:44-50. [PubMed: 22260664]

15. McNamara P, et al. Regulation of CLOCK and MOP4 by nuclear hormone receptors in the vasculature: a humoral mechanism to reset a peripheral clock. Cell. 2001; 105:877-889. [PubMed: 11439184]

16. Albrecht U. Timing to Perfection: The Biology of Central and Peripheral Circadian Clocks. Neuron. 2012; 74:246-260. [PubMed: 22542179]

17. Mohawk JA, et al. Central and peripheral circadian clocks in mammals. Annu Rev Neurosci. 2012; 35:445-462. [PubMed: 22483041]

18. Mistlberger RE, Antle MC. Entrainment of circadian clocks in mammals by arousal and food. Essays Biochem. 2011; 49:119-136. [PubMed: 21819388]

19. Laposky AD, et al. Sleep and circadian rhythms: Key components in the regulation of energy metabolism. FEBS Lett. 2008; 582:142-151. [PubMed: 17707819]

20. Cajochen, C., et al. What Keeps Us Awake? - the Role of Clocks and Hourglasses, Light, and Melatonin. In: Clow, Angela; Thorn, Lisa, editors. International Review of Neurobiology. Vol. 93. Academic Press; 2010. p. 57-90. 
21. Hastings $\mathrm{MH}$, et al. A clockwork web: circadian timing in brain and periphery, in health and disease. Nat Rev Neurosci. 2003; 4:649-661. [PubMed: 12894240]

22. Maywood ES, et al. Circadian timing in health and disease. Prog Brain Res. 2006; 153:253-269. [PubMed: 16876580]

23. Navara KJ, Nelson RJ. The dark side of light at night: physiological, epidemiological, and ecological consequences. J Pineal Res. 2007; 43:215-224. [PubMed: 17803517]

24. Colwell CS. Linking neural activity and molecular oscillations in the SCN. Nat Rev Neurosci. 2011; 12:553-569. [PubMed: 21886186]

25. Martino TA, et al. Circadian rhythm disorganization produces profound cardiovascular and renal disease in hamsters. Am J Physiol Regul Integr Comp Physiol. 2008; 294:R1675-1683. [PubMed: 18272659]

26. Lamia KA, et al. Physiological significance of a peripheral tissue circadian clock. Proc Natl Acad Sci U S A. 2008; 105:15172-15177. [PubMed: 18779586]

27. Scheer FAJL, et al. Adverse metabolic and cardiovascular consequences of circadian misalignment. Proc Natl Acad Sci U S A. 2009; 106:4453-4458. [PubMed: 19255424]

28. Czeisler CA. Perspective: casting light on sleep deficiency. Nature. 2013; 497:S13. [PubMed: 23698501]

29. Lewy AJ, et al. Light suppresses melatonin secretion in humans. Science. 1980; 210:1267-1269. [PubMed: 7434030]

30. Jung CM, et al. Acute effects of bright light exposure on cortisol levels. J Biol Rhythms. 2010; 25:208-216. [PubMed: 20484692]

31. Chang AM, et al. Human responses to bright light of different durations. J Physiol. 2012; 590:3103-3112. [PubMed: 22526883]

32. Chellappa SL, et al. Acute exposure to evening blue-enriched light impacts on human sleep. J Sleep Res. 201310.1111/jsr.12050

33. Gallant AR, et al. The night-eating syndrome and obesity. Obes Rev Off J Int Assoc Study Obes. 2012; 13:528-536.

34. Knutsson A. Health disorders of shift workers. Occup Med Oxf Engl. 2003; 53:103-108.

35. Haus EL, Smolensky MH. Shift work and cancer risk: Potential mechanistic roles of circadian disruption, light at night, and sleep deprivation. Sleep Med Rev. 201210.1016/j.smrv.2012.08.003

36. Rüger M, Scheer FAJL. Effects of circadian disruption on the cardiometabolic system. Rev Endocr Metab Disord. 2009; 10:245-260. [PubMed: 19784781]

37. Benshoff HM, et al. Suppression of pineal melatonin in Peromyscus leucopus by different monochromatic wavelengths of visible and near-ultraviolet light (UV-A). Brain Res. 1987; 420:397-402. [PubMed: 3676772]

38. Kalsbeek A, et al. GABA release from suprachiasmatic nucleus terminals is necessary for the lightinduced inhibition of nocturnal melatonin release in the rat. Neuroscience. 1999; 91:453-461. [PubMed: 10366002]

39. Bedrosian TA, et al. Light at Night Alters Daily Patterns of Cortisol and Clock Proteins in Female Siberian Hamsters. J Neuroendocrinol. 201310.1111/jne.12036

40. Sakamoto K, Ishida N. Light-induced phase-shifts in the circadian expression rhythm of mammalian Period genes in the mouse heart. Eur J Neurosci. 2000; 12:4003-4006. [PubMed: 11069596]

41. Szántóová K, et al. Effect of phase delay lighting rotation schedule on daily expression of per2, bmal1, rev-erba, ppara, and pdk4 genes in the heart and liver of Wistar rats. Mol Cell Biochem. 2011; 348:53-60. [PubMed: 21076970]

42. Fonken LK, et al. Dim light at night disrupts molecular circadian rhythms and increases body weight. J Biol Rhythms. 2013; 28:262-271. [PubMed: 23929553]

43. LeGates TA, et al. Aberrant light directly impairs mood and learning through melanopsinexpressing neurons. Nature. 2012; 491:594-598. [PubMed: 23151476]

44. Fonken LK, Nelson RJ. Dim light at night increases depressive-like responses in male C3H/ HeNHsd mice. Behav Brain Res. 2013; 243:74-78. [PubMed: 23291153] 
45. Anisimov VN, et al. Light-at-Night-Induced Circadian Disruption, Cancer, and Aging. Curr Aging Sci. 2012

46. Summa KC, et al. Environmental perturbation of the circadian clock disrupts pregnancy in the mouse. PloS One. 2012; 7:e37668. [PubMed: 22649550]

47. Castanon-Cervantes O, et al. Dysregulation of inflammatory responses by chronic circadian disruption. J Immunol Baltim Md 1950. 2010; 185:5796-5805.

48. Filipski E, et al. Circadian disruption accelerates liver carcinogenesis in mice. Mutat Res. 2009; 680:95-105. [PubMed: 19833225]

49. Oishi K, Ohkura N. Chronic circadian clock disruption induces expression of the cardiovascular risk factor plasminogen activator inhibitor-1 in mice. Blood Coagul Fibrinolysis. Int J Haemost Thromb. 2013; 24:106-108.

50. Barclay JL, et al. Circadian desynchrony promotes metabolic disruption in a mouse model of shiftwork. PloS One. 2012; 7:e37150. [PubMed: 22629359]

51. Fonken LK, et al. Influence of light at night on murine anxiety- and depressive-like responses. Behav Brain Res. 2009; 205:349-354. [PubMed: 19591880]

52. Damiola F, et al. Restricted feeding uncouples circadian oscillators in peripheral tissues from the central pacemaker in the suprachiasmatic nucleus. Genes Dev. 2000; 14:2950-2961. [PubMed: 11114885]

53. Stokkan KA, et al. Entrainment of the circadian clock in the liver by feeding. Science. 2001; 291:490-493. [PubMed: 11161204]

54. Van Someren EJ. Circadian and sleep disturbances in the elderly. Exp Gerontol. 2000; 35:12291237. [PubMed: 11113604]

55. Roenneberg T, et al. Epidemiology of the human circadian clock. Sleep Med Rev. 2007; 11:429_ 438. [PubMed: 17936039]

56. Hofman MA, Swaab DF. Living by the clock: the circadian pacemaker in older people. Ageing Res Rev. 2006; 5:33-51. [PubMed: 16126012]

57. Skene DJ, Swaab DF. Melatonin rhythmicity: effect of age and Alzheimer's disease. Exp Gerontol. 2003; 38:199-206. [PubMed: 12543278]

58. Schmidt C, et al. Age-related changes in sleep and circadian rhythms: impact on cognitive performance and underlying neuroanatomical networks. Front Neurol. 2012; 3:118. [PubMed: 22855682]

59. Cajochen C, et al. Age-related changes in the circadian and homeostatic regulation of human sleep. Chronobiol Int. 2006; 23:461-474. [PubMed: 16687319]

60. Pagani L, et al. Serum factors in older individuals change cellular clock properties. Proc Natl Acad Sci U S A. 2011; 108:7218-7223. [PubMed: 21482780]

61. Nakamura TJ, et al. Age-related decline in circadian output. J Neurosci Off J Soc Neurosci. 2011; 31:10201-10205.

62. Asai M, et al. Circadian profile of Per gene mRNA expression in the suprachiasmatic nucleus, paraventricular nucleus, and pineal body of aged rats. J Neurosci Res. 2001; 66:1133-1139. [PubMed: 11746446]

63. Beynon AL, et al. Age and time of day influences on the expression of transforming growth factorbeta and phosphorylated SMAD3 in the mouse suprachiasmatic and paraventricular nuclei. Neuroimmunomodulation. 2009; 16:392-399. [PubMed: 19609088]

64. Kawakami F, et al. Loss of day-night differences in VIP mRNA levels in the suprachiasmatic nucleus of aged rats. Neurosci Lett. 1997; 222:99-102. [PubMed: 9111738]

65. Yamazaki S, et al. Effects of aging on central and peripheral mammalian clocks. Proc Natl Acad Sci U S A. 2002; 99:10801-10806. [PubMed: 12149444]

66. Davidson AJ, et al. Chronic jet-lag increases mortality in aged mice. Curr Biol CB. 2006; 16:R914-916.

67. Sellix MT, et al. Aging differentially affects the re-entrainment response of central and peripheral circadian oscillators. J Neurosci Off J Soc Neurosci. 2012; 32:16193-16202.

68. Davidson AJ, et al. Resetting of central and peripheral circadian oscillators in aged rats. Neurobiol Aging. 2008; 29:471-477. [PubMed: 17129640] 
69. Videnovic A, Golombek D. Circadian and sleep disorders in Parkinson's disease. Exp Neurol. 201210.1016/j.expneurol.2012.08.018

70. Harper DG, et al. Disturbance of endogenous circadian rhythm in aging and Alzheimer disease. Am J Geriatr Psychiatry Off J Am Assoc Geriatr Psychiatry. 2005; 13:359-368.

71. Cermakian N, et al. Circadian clock gene expression in brain regions of Alzheimer 's disease patients and control subjects. J Biol Rhythms. 2011; 26:160-170. [PubMed: 21454296]

72. Hahn EA, et al. A Change in Sleep Pattern May Predict Alzheimer Disease. Am J Geriatr Psychiatry Off J Am Assoc Geriatr Psychiatry. 201310.1016/j.jagp.2013.04.015

73. Lim ASP, et al. Sleep Fragmentation and the Risk of Incident Alzheimer's Disease and Cognitive Decline in Older Persons. Sleep. 2013; 36:1027-1032. [PubMed: 23814339]

74. Sterniczuk R, et al. Sleep Disturbance is Associated with Incident Dementia and Mortality. Curr Alzheimer Res. 2013; 10:767-775. [PubMed: 23905991]

75. Harper DG, et al. Dorsomedial SCN neuronal subpopulations subserve different functions in human dementia. Brain J Neurol. 2008; 131:1609-1617.

76. Hardeland R, et al. Circadian rhythms, oxidative stress, and antioxidative defense mechanisms. Chronobiol Int. 2003; 20:921-962. [PubMed: 14680136]

77. Antoch MP, Kondratov RV. Circadian proteins and genotoxic stress response. Circ Res. 2010; 106:68-78. [PubMed: 20056947]

78. Spengler ML, et al. Core circadian protein CLOCK is a positive regulator of NF- $\mathrm{BB}-$ mediated transcription. Proc Natl Acad Sci U S A. 2012; 109:E2457-2465. [PubMed: 22895791]

79. Perry VH. The influence of systemic inflammation on inflammation in the brain: implications for chronic neurodegenerative disease. Brain Behav Immun. 2004; 18:407-413. [PubMed: 15265532]

80. Willison LD, et al. Circadian dysfunction may be a key component of the non-motor symptoms of Parkinson's disease: Insights from a transgenic mouse model. Exp Neurol. 2013; 243:57-66. [PubMed: 23353924]

81. Kudo T, et al. Dysfunctions in circadian behavior and physiology in mouse models of Huntington's disease. Exp Neurol. 2011; 228:80-90. [PubMed: 21184755]

82. Kudo T, et al. Circadian dysfunction in a mouse model of Parkinson's disease. Exp Neurol. 2011; 232:66-75. [PubMed: 21864527]

83. Maywood ES, et al. Disruption of peripheral circadian timekeeping in a mouse model of Huntington's disease and its restoration by temporally scheduled feeding. J Neurosci Off J Soc Neurosci. 2010; 30:10199-10204.

84. Oakeshott S, et al. Circadian Abnormalities in Motor Activity in a BAC Transgenic Mouse Model of Huntington's Disease. PLoS Curr. 2011; 3:RRN1225. [PubMed: 21479110]

85. Duncan MJ, et al. Effects of aging and genotype on circadian rhythms, sleep, and clock gene expression in APPxPS1 knock-in mice, a model for Alzheimer's disease. Exp Neurol. 2012; 236:249-258. [PubMed: 22634208]

86. Boutrel B, Koob GF. What keeps us awake: the neuropharmacology of stimulants and wakefulness-promoting medications. Sleep. 2004; 27:1181-1194. [PubMed: 15532213]

87. Liu AC, et al. Mammalian circadian signaling networks and therapeutic targets. Nat Chem Biol. 2007; 3:630-639. [PubMed: 17876320]

88. Freeman GM, et al. GABA Networks Destabilize Genetic Oscillations in the Circadian Pacemaker. Neuron. 2013; 78:799-806. [PubMed: 23764285]

89. Holick MF, Chen TC. Vitamin D deficiency: a worldwide problem with health consequences. Am J Clin Nutr. 2008; 87:1080S-1086S. [PubMed: 18400738]

90. Khalsa SBS, et al. A phase response curve to single bright light pulses in human subjects. J Physiol. 2003; 549:945-952. [PubMed: 12717008]

91. Rollag MD, et al. Melanopsin, ganglion-cell photoreceptors, and mammalian photoentrainment. J Biol Rhythms. 2003; 18:227-234. [PubMed: 12828280]

92. Schmidt TM, et al. Intrinsically photosensitive retinal ganglion cells: many subtypes, diverse functions. Trends Neurosci. 2011; 34:572-580. [PubMed: 21816493]

93. Lucas RJ, et al. How rod, cone, and melanopsin photoreceptors come together to enlighten the mammalian circadian clock. Prog Brain Res. 2012; 199:1-18. [PubMed: 22877656] 
94. Nakamura W, et al. In Vivo Monitoring of Circadian Timing in Freely Moving Mice. Curr Biol. 2008; 18:381-385. [PubMed: 18334203]

95. Shigeyoshi Y, et al. Light-induced resetting of a mammalian circadian clock is associated with rapid induction of the mPer1 transcript. Cell. 1997; 91:1043-1053. [PubMed: 9428526]

96. Kornhauser JM, et al. Photic and circadian regulation of c-fos gene expression in the hamster suprachiasmatic nucleus. Neuron. 1990; 5:127-134. [PubMed: 2116813]

97. Albrecht $\mathrm{U}$, et al. A differential response of two putative mammalian circadian regulators, mper1 and mper2, to light. Cell. 1997; 91:1055-1064. [PubMed: 9428527]

98. Davidson AJ, et al. Visualizing jet lag in the mouse suprachiasmatic nucleus and peripheral circadian timing system. Eur J Neurosci. 2009; 29:171-180. [PubMed: 19032592]

99. Shuboni D, Yan L. Nighttime dim light exposure alters the responses of the circadian system. Neuroscience. 2010; 170:1172-1178. [PubMed: 20705120]

100. Duffy JF, Czeisler CA. Effect of Light on Human Circadian Physiology. Sleep Med Clin. 2009; 4:165-177. [PubMed: 20161220]

101. Adidharma $\mathrm{W}$, et al. Orexinergic signaling mediates light-induced neuronal activation in the dorsal raphe nucleus. Neuroscience. 2012; 220:201-207. [PubMed: 22710065]

102. Ruger M, Scheer FAJL. Effects of circadian disruption on cardiometabolic system. Rev Endocr Metab Disord. 2009; 10:245-260. [PubMed: 19784781]

103. Barion A, Zee PC. A clinical approach to circadian rhythm sleep disorders. Sleep Med. 2007; 8:566-577. [PubMed: 17395535]

104. Burgess HJ, et al. Bright light, dark and melatonin can promote circadian adaptation in night shift workers. Sleep Med Rev. 2002; 6:407-420. [PubMed: 12531129]

105. Magnusson A, Boivin D. Seasonal affective disorder: an overview. Chronobiol Int. 2003; 20:189207. [PubMed: 12723880]

106. Wirz-Justice A, et al. Brightening depression. Science. 2004; 303:467-469. [PubMed: 14739440]

107. Lieverse R, et al. Bright light treatment in elderly patients with nonseasonal major depressive disorder: a randomized placebo-controlled trial. Arch Gen Psychiatry. 2011; 68:61-70. [PubMed: 21199966]

108. Friedman L, et al. Brief morning light treatment for sleep/wake disturbances in older memoryimpaired individuals and their caregivers. Sleep Med. 2012; 13:546-549. [PubMed: 22406033]

109. Royer M, et al. Light therapy for seniors in long term care. J Am Med Dir Assoc. 2012; 13:100102. [PubMed: 21683660]

110. Riemersma-van der Lek RF, et al. Effect of bright light and melatonin on cognitive and noncognitive function in elderly residents of group care facilities: a randomized controlled trial. JAMA J Am Med Assoc. 2008; 299:2642-2655.

111. Yamadera $\mathrm{H}$, et al. Effects of bright light on cognitive and sleep wake (circadian) rhythm disturbances in Alzheimer-type dementia. Psychiatry Clin Neurosci. 2000; 54:352-353. [PubMed: 11186110]

112. Wu YH, Swaab DF. Disturbance and strategies for reactivation of the circadian rhythm system in aging and Alzheimer's disease. Sleep Med. 2007; 8:623-636. [PubMed: 17383938]

113. Willis GL, et al. A historical justification for and retrospective analysis of the systematic application of light therapy in Parkinson's disease. Rev Neurosci. 2012; 23:199-226. [PubMed: 22499678]

114. Rutten S, et al. Bright Light Therapy in Parkinson's Disease: An Overview of the Background and Evidence. Park Dis. 2012; 2012:1-9.

115. Ancoli-Israel S, et al. Increased Light Exposure Consolidates Sleep and Strengthens Circadian Rhythms in Severe Alzheimer's Disease Patients. Behav Sleep Med. 2003; 1:22-36. [PubMed: 15600135]

116. Benedetti F. Antidepressant chronotherapeutics for bipolar depression. Dialogues Clin Neurosci. 2012; 14:401-411. [PubMed: 23393416]

117. Dowling GA, et al. Melatonin and Bright-Light Treatment for Rest Activity Disruption in Institutionalized Patients with Alzheimer's Disease. J Am Geriatr Soc. 2008; 56:239-246. [PubMed: 18070004] 
118. Friedman L, et al. Scheduled bright light for treatment of insomnia in older adults. J Am Geriatr Soc. 2009; 57:441-452. [PubMed: 19187411]

119. Ancoli-Israel S, et al. Effect of light treatment on sleep and circadian rhythms in demented nursing home patients. J Am Geriatr Soc. 2002; 50:282-289. [PubMed: 12028210]

120. Viola AU, et al. Blue-enriched white light in the workplace improves self-reported alertness, performance and sleep quality. Scand J Work Environ Health. 2008; 34:297-306. [PubMed: 18815716]

121. Wright KP Jr, et al. Entrainment of the human circadian clock to the natural light-dark cycle. Curr Biol CB. 2013; 23:1554-1558.

122. Hoogerwerf WA. Biologic clocks and the gut. Curr Gastroenterol Rep. 2006; 8:353-359. [PubMed: 16968601]

123. Bass J. Circadian topology of metabolism. Nature. 2012; 491:348-356. [PubMed: 23151577]

124. Froy O. Metabolism and circadian rhythms--implications for obesity. Endocr Rev. 2010; 31:1-24. [PubMed: 19854863]

125. Cailotto $\mathrm{C}$, et al. The suprachiasmatic nucleus controls the daily variation of plasma glucose via the autonomic output to the liver: are the clock genes involved? Eur J Neurosci. 2005; 22:25312540. [PubMed: 16307595]

126. Shibata S. Neural regulation of the hepatic circadian rhythm. Anat Rec A Discov Mol Cell Evol Biol. 2004; 280:901-909. [PubMed: 15382011]

127. Guo H, et al. Differential control of peripheral circadian rhythms by suprachiasmatic-dependent neural signals. Proc Natl Acad Sci U S A. 2005; 102:3111-3116. [PubMed: 15710878]

128. Paschos GK, et al. Obesity in mice with adipocyte-specific deletion of clock component Arntl. Nat Med. 2012; 18:1768-1777. [PubMed: 23142819]

129. Shimba S, et al. Deficient of a clock gene, brain and muscle Arnt-like protein-1 (BMAL1), induces dyslipidemia and ectopic fat formation. PloS One. 2011; 6:e25231. [PubMed: 21966465]

130. Turek FW, et al. Obesity and metabolic syndrome in circadian Clock mutant mice. Science. 2005; 308:1043-1045. [PubMed: 15845877]

131. Qian J, et al. Consequences of exposure to light at night on the pancreatic islet circadian clock and function in rats. Diabetes. 201310.2337/db12-1543

132. Rudic RD, et al. BMAL1 and CLOCK, two essential components of the circadian clock, are involved in glucose homeostasis. PLoS Biol. 2004; 2:e377. [PubMed: 15523558]

133. Coomans CP, et al. Detrimental effects of constant light exposure and high-fat diet on circadian energy metabolism and insulin sensitivity. FASEB J Off Publ Fed Am Soc Exp Biol. 2013; 27:1721-1732.

134. Gale JE, et al. Disruption of circadian rhythms accelerates development of diabetes through pancreatic beta-cell loss and dysfunction. J Biol Rhythms. 2011; 26:423-433. [PubMed: 21921296]

135. Spiegel K, et al. Effects of poor and short sleep on glucose metabolism and obesity risk. Nat Rev Endocrinol. 2009; 5:253-261. [PubMed: 19444258]

136. Markwald RR, et al. Impact of insufficient sleep on total daily energy expenditure, food intake, and weight gain. Proc Natl Acad Sci U S A. 2013; 110:5695-5700. [PubMed: 23479616]

137. Kuroda H, et al. Meal frequency patterns determine the phase of mouse peripheral circadian clocks. Sci Reports. 2012; 2:711.

138. Hirao A, et al. Combination of starvation interval and food volume determines the phase of liver circadian rhythm in Per2::Luc knock-in mice under two meals per day feeding. Am J Physiol Gastrointest Liver Physiol. 2010; 299:G1045-G1053. [PubMed: 20847299]

139. Oishi K, et al. Low-carbohydrate, high-protein diet affects rhythmic expression of gluconeogenic regulatory and circadian clock genes in mouse peripheral tissues. Chronobiol Int. 2012; 29:799809. [PubMed: 22823864]

140. Hatori M, et al. Time-restricted feeding without reducing caloric intake prevents metabolic diseases in mice fed a high-fat diet. Cell Metab. 2012; 15:848-860. [PubMed: 22608008]

141. Kohsaka A, et al. High-fat diet disrupts behavioral and molecular circadian rhythms in mice. Cell Metab. 2007; 6:414-421. [PubMed: 17983587] 
142. Arble DM, et al. Circadian timing of food intake contributes to weight gain. Obes Silver Spring Md. 2009; 17:2100-2102.

143. Wu L, Reddy AB. Disrupting rhythms: diet-induced obesity impairs diurnal rhythms in metabolic tissues. Diabetes. 2013; 62:1829-1830. [PubMed: 23704528]

144. Karatsoreos IN, et al. Disruption of circadian clocks has ramifications for metabolism, brain, and behavior. Proc Natl Acad Sci U S A. 2011; 108:1657-1662. [PubMed: 21220317]

145. Bray MS, et al. Quantitative analysis of light-phase restricted feeding reveals metabolic dyssynchrony in mice. Int J Obes 2005. 201210.1038/ijo.2012.137

146. Vieira E, et al. The clock gene Rev-erba regulates pancreatic $\beta$-cell function: modulation by leptin and high-fat diet. Endocrinology. 2012; 153:592-601. [PubMed: 22166979]

147. Sherman H, et al. Timed high-fat diet resets circadian metabolism and prevents obesity. FASEB J Off Publ Fed Am Soc Exp Biol. 2012; 26:3493-3502.

148. Vollmers $\mathrm{C}$, et al. Time of feeding and the intrinsic circadian clock drive rhythms in hepatic gene expression. Proc Natl Acad Sci. 2009; 106:21453-21458. [PubMed: 19940241]

149. Monk TH, et al. Regularity of daily life in relation to personality, age, gender, sleep quality and circadian rhythms. J Sleep Res. 1994; 3:196-205. [PubMed: 10607126]

150. Zisberg A, et al. Contribution of routine to sleep quality in community elderly. Sleep. 2010; 33:509-514. [PubMed: 20394320]

151. Câmara Magalhães S, et al. Lifestyle regularity measured by the social rhythm metric in Parkinson's disease. Chronobiol Int. 2005; 22:917-924. [PubMed: 16298776]

152. Frank E, et al. Inducing lifestyle regularity in recovering bipolar disorder patients: Results from the maintenance therapies in bipolar disorder protocol. Biol Psychiatry. 1997; 41:1165-1173. [PubMed: 9171907]

153. Young KW, Greenwood CE. Shift in diurnal feeding patterns in nursing home residents with Alzheimer's disease. J Gerontol A Biol Sci Med Sci. 2001; 56:M700-706. [PubMed: 11682578]

154. Reebs SG, Mrosovsky N. Effects of induced wheel running on the circadian activity rhythms of Syrian hamsters: entrainment and phase response curve. J Biol Rhythms. 1989; 4:39-48. [PubMed: 2519579]

155. Mrosovsky N, Salmon PA. A behavioural method for accelerating re-entrainment of rhythms to new light|[mdash]|dark cycles. 1987:372-373. Publ Online 26 Novemb 1987. doi: $101038330372 \mathrm{a} 0330$.

156. Dallmann R, Mrosovsky N. Scheduled wheel access during daytime: A method for studying conflicting zeitgebers. Physiol Behav. 2006; 88:459-465. [PubMed: 16780903]

157. Castillo C, et al. Restricted wheel access following a light cycle inversion slows re-entrainment without internal desynchrony as measured in Per2Luc mice. Neuroscience. 2011; 182:169-176. [PubMed: 21392557]

158. Schaap J, Meijer JH. Opposing effects of behavioural activity and light on neurons of the suprachiasmatic nucleus. Eur J Neurosci. 2001; 13:1955-1962. [PubMed: 11403689]

159. Houben $\mathrm{T}$, et al. Correlation with behavioral activity and rest implies circadian regulation by SCN neuronal activity levels. J Biol Rhythms. 2009; 24:477-487. [PubMed: 19926807]

160. Maywood ES, et al. Rapid down-regulation of mammalian period genes during behavioral resetting of the circadian clock. Proc Natl Acad Sci U S A. 1999; 96:15211-15216. [PubMed: 10611364]

161. Schroeder AM, et al. Voluntary scheduled exercise alters diurnal rhythms of behaviour, physiology and gene expression in wild-type and vasoactive intestinal peptide-deficient mice. $\mathrm{J}$ Physiol. 2012; 590:6213-6226. [PubMed: 22988135]

162. Buxton OM, et al. Exercise elicits phase shifts and acute alterations of melatonin that vary with circadian phase. Am J Physiol Regul Integr Comp Physiol. 2003; 284:R714-724. [PubMed: 12571075]

163. Baehr EK, et al. Circadian phase-shifting effects of nocturnal exercise in older compared with young adults. Am J Physiol Regul Integr Comp Physiol. 2003; 284:R1542-1550. [PubMed: 12573982] 
164. Yamanaka Y, et al. Effects of physical exercise on human circadian rhythms. Sleep Biol Rhythms. 2006; 4:199-206.

165. Atkinson G, et al. Exercise as a synchroniser of human circadian rhythms: an update and discussion of the methodological problems. Eur J Appl Physiol. 2007; 99:331-341. [PubMed: 17165050]

166. Buxton OM, et al. Roles of intensity and duration of nocturnal exercise in causing phase delays of human circadian rhythms. Am J Physiol. 1997; 273:E536-542. [PubMed: 9316443]

167. Miyazaki T, et al. Phase-advance shifts of human circadian pacemaker are accelerated by daytime physical exercise. Am J Physiol Regul Integr Comp Physiol. 2001; 281:R197-205. [PubMed: 11404294]

168. Schmidt KP, et al. Locomotor activity accelerates the adjustment of the temperature rhythm in shiftwork. J Interdisiplinary Cycle Res. 1990; 21:243-245.

169. Eastman CI, et al. Phase-shifting human circadian rhythms with exercise during the night shift. Physiol Behav. 1995; 58:1287-1291. [PubMed: 8623034]

170. Leise TL, et al. Voluntary exercise can strengthen the circadian system in aged mice. Age Dordr Neth. 201310.1007/s11357-012-9502-y

171. Welsh D, et al. Effect of running wheel availability on circadian patterns of sleep and wakefulness in mice. Physiol Behav. 1988; 43:771-777. [PubMed: 3237790]

172. Power A, et al. Rhythm-promoting actions of exercise in mice with deficient neuropeptide signaling. J Biol Rhythms. 2010; 25:235-246. [PubMed: 20679493]

173. Someren EJWV, et al. Long-Term Fitness Training Improves the Circadian Rest-Activity Rhythm in Healthy Elderly Males. J Biol Rhythms. 1997; 12:146-156. [PubMed: 9090568]

174. Reid KJ, et al. Aerobic exercise improves self-reported sleep and quality of life in older adults with insomnia. Sleep Med. 2010; 11:934-940. [PubMed: 20813580]

175. Benloucif S, et al. Morning or evening activity improves neuropsychological performance and subjective sleep quality in older adults. Sleep. 2004; 27:1542-1551. [PubMed: 15683146]

176. Fuller PM, et al. Neurobiology of the sleep-wake cycle: sleep architecture, circadian regulation, and regulatory feedback. J Biol Rhythms. 2006; 21:482-493. [PubMed: 17107938]

177. Kalsbeek A, Buijs RM. Output pathways of the mammalian suprachiasmatic nucleus: coding circadian time by transmitter selection and specific targeting. Cell Tissue Res. 2002; 309:109_ 118. [PubMed: 12111541]

178. Kalsbeek A, et al. SCN outputs and the hypothalamic balance of life. J Biol Rhythms. 2006; 21:458-469. [PubMed: 17107936]

179. Czeisler CA, Gooley JJ. Sleep and circadian rhythms in humans. Cold Spring Harb Symp Quant Biol. 2007; 72:579-597. [PubMed: 18419318]

180. Deboer T, et al. Sleep states alter activity of suprachiasmatic nucleus neurons. Nat Neurosci. 2003; 6:1086-1090. [PubMed: 12958601]

181. Möller-Levet CS, et al. Effects of insufficient sleep on circadian rhythmicity and expression amplitude of the human blood transcriptome. Proc Natl Acad Sci U S A. 2013; 110:E1132-1141. [PubMed: 23440187]

182. Mistlberger RE. Circadian regulation of sleep in mammals: role of the suprachiasmatic nucleus. Brain Res Brain Res Rev. 2005; 49:429-454. [PubMed: 16269313]

183. Fisher SP, et al. The circadian control of sleep. Handb Exp Pharmacol. 201310.1007/978-3-642-25950-0_7

184. Pallier PN, et al. Pharmacological imposition of sleep slows cognitive decline and reverses dysregulation of circadian gene expression in a transgenic mouse model of Huntington's disease. J Neurosci Off J Soc Neurosci. 2007; 27:7869-7878.

185. Pallier PN, Morton AJ. Management of sleep/wake cycles improves cognitive function in a transgenic mouse model of Huntington's disease. Brain Res. 2009; 1279:90-98. [PubMed: 19450569]

186. Zhou JN, et al. VIP neurons in the human SCN in relation to sex, age, and Alzheimer's disease. Neurobiol Aging. 1995; 16:571-576. [PubMed: 8544907] 
187. Van Wamelen DJ, et al. Suprachiasmatic Nucleus Neuropeptide Expression in Patients with Huntington's Disease. Sleep. 2013; 36:117-125. [PubMed: 23288978]

188. Pantazopoulos $\mathrm{H}$, et al. Chronic stimulation of the hypothalamic vasoactive intestinal peptide receptor lengthens circadian period in mice and hamsters. Am J Physiol Regul Integr Comp Physiol. 2010; 299:R379-385. [PubMed: 20463182]

189. Kiessling S, et al. Adrenal glucocorticoids have a key role in circadian resynchronization in a mouse model of jet lag. J Clin Invest. 2010; 120:2600-2609. [PubMed: 20577050]

190. Pevet P, Challet E. Melatonin: both master clock output and internal time-giver in the circadian clocks network. J Physiol Paris. 2011; 105:170-182. [PubMed: 21914478]

191. Durgan DJ, et al. The intrinsic circadian clock within the cardiomyocyte. Am J Physiol Heart Circ Physiol. 2005; 289:H1530-1541. [PubMed: 15937094]

192. Vitaterna MH, et al. The mouse Clock mutation reduces circadian pacemaker amplitude and enhances efficacy of resetting stimuli and phase-response curve amplitude. Proc Natl Acad Sci U S A. 2006; 103:9327-9332. [PubMed: 16754844]

193. Dubocovich ML. Melatonin receptors: role on sleep and circadian rhythm regulation. Sleep Med. 2007; 8(Suppl 3):34-42. [PubMed: 18032103]

194. Slominski RM, et al. Melatonin membrane receptors in peripheral tissues: distribution and functions. Mol Cell Endocrinol. 2012; 351:152-166. [PubMed: 22245784]

195. Lyssenko V, et al. Common variant in MTNR1B associated with increased risk of type 2 diabetes and impaired early insulin secretion. Nat Genet. 2009; 41:82-88. [PubMed: 19060908]

196. Samimi-Fard S, et al. A case-control study of melatonin receptor type 1A polymorphism and acute myocardial infarction in a Spanish population. J Pineal Res. 2011; 51:400-404. [PubMed: 21635358]

197. Natarajan R, et al. Melatonin pathway genes are associated with progressive subtypes and disability status in multiple sclerosis among Finnish patients. J Neuroimmunol. 2012; 250:106110. [PubMed: 22698518]

198. Gaecki P, et al. Single-nucleotide polymorphisms and mRNA expression for melatonin synthesis rate-limiting enzyme in recurrent depressive disorder. J Pineal Res. 2010; 48:311-317. [PubMed: 20433639]

199. San L, Arranz B. Agomelatine: A novel mechanism of antidepressant action involving the melatonergic and the serotonergic system. Eur Psychiatry. 2008; 23:396-402. [PubMed: 18583104]

200. Schernhammer ES, Hankinson SE. Urinary melatonin levels and breast cancer risk. J Natl Cancer Inst. 2005; 97:1084-1087. [PubMed: 16030307]

201. Liu RY, et al. Decreased melatonin levels in postmortem cerebrospinal fluid in relation to aging, Alzheimer's disease, and apolipoprotein E-epsilon4/4 genotype. J Clin Endocrinol Metab. 1999; 84:323-327. [PubMed: 9920102]

202. Aziz NA, et al. Delayed onset of the diurnal melatonin rise in patients with Huntington's disease. J Neurol. 2009; 256:1961-1965. [PubMed: 19562249]

203. Pévet $\mathrm{P}$, et al. Melatonin in the multi-oscillatory mammalian circadian world. Chronobiol Int. 2006; 23:39-51. [PubMed: 16687278]

204. Lemoine P, Zisapel N. Prolonged-release formulation of melatonin (Circadin) for the treatment of insomnia. Expert Opin Pharmacother. 2012; 13:895-905. [PubMed: 22429105]

205. Srinivasan V, et al. Therapeutic potential of melatonin and its analogs in Parkinson's disease: focus on sleep and neuroprotection. Ther Adv Neurol Disord. 2011; 4:297-317. [PubMed: 22010042]

206. Cardinali DP, et al. The use of chronobiotics in the resynchronization of the sleep-wake cycle. Cancer Causes Control CCC. 2006; 17:601-609. [PubMed: 16596316]

207. Eckerberg B, et al. Melatonin treatment effects on adolescent students' sleep timing and sleepiness in a placebo-controlled crossover study. Chronobiol Int. 2012; 29:1239-1248. [PubMed: 23005039]

208. Scheer FAJL, et al. Daily nighttime melatonin reduces blood pressure in male patients with essential hypertension. Hypertension. 2004; 43:192-197. [PubMed: 14732734] 
209. Scheer FAJL, et al. Repeated melatonin supplementation improves sleep in hypertensive patients treated with beta-blockers: a randomized controlled trial. Sleep. 2012; 35:1395-1402. [PubMed: 23024438]

210. Bjorvatn B, et al. Randomized placebo-controlled field study of the effects of bright light and melatonin in adaptation to night work. Scand J Work Environ Health. 2007; 33:204-214. [PubMed: 17572830]

211. Lanfumey L, et al. Biological rhythms and melatonin in mood disorders and their treatments. Pharmacol Ther. 2013; 138:176-184. [PubMed: 23348014]

212. Reeth OV, et al. Melatonin or a melatonin agonist corrects age-related changes in circadian response to environmental stimulus. Am J Physiol - Regul Integr Comp Physiol. 2001; 280:R1582-R1591. [PubMed: 11294784]

213. Li J, et al. Lithium impacts on the amplitude and period of the molecular circadian clockwork. PloS One. 2012; 7:e33292. [PubMed: 22428012]

214. Yin L, et al. Nuclear receptor Rev-erbalpha is a critical lithium-sensitive component of the circadian clock. Science. 2006; 311:1002-1005. [PubMed: 16484495]

215. Gould TD, Manji HK. Glycogen Synthase Kinase-3: a Putative Molecular Target for Lithium Mimetic Drugs. Neuropsychopharmacology. 2005; 30:1223-1237. [PubMed: 15827567]

216. Johansson AS, et al. Valproic acid phase shifts the rhythmic expression of Period2::Luciferase. J Biol Rhythms. 2011; 26:541-551. [PubMed: 22215612]

217. Um JH, et al. Activation of 5'-AMP-activated Kinase with Diabetes Drug Metformin Induces Casein Kinase I $\varepsilon(\mathrm{CKI} \varepsilon)$-dependent Degradation of Clock Protein mPer2. J Biol Chem. 2007; 282:20794-20798. [PubMed: 17525164]

218. Barnea M, et al. Metformin affects the circadian clock and metabolic rhythms in a tissue-specific manner. Biochim Biophys Acta. 2012; 1822:1796-1806. [PubMed: 22968146]

219. Chen Z, et al. Small molecule modifiers of circadian clocks. Cell Mol Life Sci CMLS. 201210.1007/s00018-012-1207-y

220. Caton PW, et al. Metformin opposes impaired AMPK and SIRT1 function and deleterious changes in core clock protein expression in white adipose tissue of genetically-obese $\mathrm{db} / \mathrm{db}$ mice. Diabetes Obes Metab. 2011; 13:1097-1104. [PubMed: 21733059]

221. Morin LP. Serotonin and the regulation of mammalian circadian rhythmicity. Ann Med. 1999; 31:12-33. [PubMed: 10219711]

222. Meyer-Bernstein EL, Morin LP. Differential serotonergic innervation of the suprachiasmatic nucleus and the intergeniculate leaflet and its role in circadian rhythm modulation. J Neurosci Off J Soc Neurosci. 1996; 16:2097-2111.

223. Smith VM, et al. Serotonergic potentiation of photic phase shifts: examination of receptor contributions and early biochemical/molecular events. Neuroscience. 2010; 165:16-27. [PubMed: 19799970]

224. Gannon RL. Serotonergic serotonin (1A) mixed agonists/antagonists elicit large-magnitude phase shifts in hamster circadian wheel-running rhythms. Neuroscience. 2003; 119:567-576. [PubMed: 12770569]

225. Rea MA, et al. Serotonergic potentiation of photic phase shifts of the circadian activity rhythm. Neuroreport. 1995; 6:1417-1420. [PubMed: 7488738]

226. Cuesta M, et al. Serotonergic activation potentiates light resetting of the main circadian clock and alters clock gene expression in a diurnal rodent. Exp Neurol. 2008; 210:501-513. [PubMed: 18190911]

227. Pail G, et al. Bright-light therapy in the treatment of mood disorders. Neuropsychobiology. 2011; 64:152-162. [PubMed: 21811085]

228. Yuan Q, et al. Serotonin modulates circadian entrainment in Drosophila. Neuron. 2005; 47:115127. [PubMed: 15996552]

229. Bedrosian TA, et al. Chronic citalopram treatment ameliorates depressive behavior associated with light at night. Behav Neurosci. 2012; 126:654-658. [PubMed: 22889310]

230. Sprouse J, et al. Fluoxetine modulates the circadian biological clock via phase advances of suprachiasmatic nucleus neuronal firing. Biol Psychiatry. 2006; 60:896-899. [PubMed: 16631132] 
231. Ishiyama T, et al. Lurasidone (SM-13496), a novel atypical antipsychotic drug, reverses MK-801induced impairment of learning and memory in the rat passive-avoidance test. Eur J Pharmacol. 2007; 572:160-170. [PubMed: 17662268]

232. Meng QJ, et al. Entrainment of disrupted circadian behavior through inhibition of casein kinase 1 (CK1) enzymes. Proc Natl Acad Sci U S A. 2010; 107:15240-15245. [PubMed: 20696890]

233. Xu Y, et al. Modeling of a human circadian mutation yields insights into clock regulation by PER2. Cell. 2007; 128:59-70. [PubMed: 17218255]

234. Solt LA, et al. Regulation of circadian behaviour and metabolism by synthetic REV-ERB agonists. Nature. 201210.1038/nature11030

235. Kumar N, et al. Regulation of adipogenesis by natural and synthetic REV-ERB ligands. Endocrinology. 2010; 151:3015-3025. [PubMed: 20427485]

236. Meng QJ, et al. Ligand modulation of REV-ERBalpha function resets the peripheral circadian clock in a phasic manner. J Cell Sci. 2008; 121:3629-3635. [PubMed: 18946026]

237. Trump RP, et al. Optimized chemical probes for REV-ERBa. J Med Chem. 2013; 56:4729-4737. [PubMed: 23656296]

238. Gibbs JE, et al. The nuclear receptor REV-ERBa mediates circadian regulation of innate immunity through selective regulation of inflammatory cytokines. Proc Natl Acad Sci U S A. 2012; 109:582-587. [PubMed: 22184247]

239. Bellet MM, et al. Pharmacological modulation of circadian rhythms by synthetic activators of the deacetylase SIRT1. Proc Natl Acad Sci U S A. 201310.1073/pnas.1214266110

240. Nakahata Y, et al. The NAD+-dependent deacetylase SIRT1 modulates CLOCK-mediated chromatin remodeling and circadian control. Cell. 2008; 134:329-340. [PubMed: 18662547]

241. Morin LP. Neuroanatomy of the extended circadian rhythm system. Exp Neurol. 2013; 243:4-20. [PubMed: 22766204]

242. Glass JD, et al. On the intrinsic regulation of neuropeptide Y release in the mammalian suprachiasmatic nucleus circadian clock. Eur J Neurosci. 2010; 31:1117-1126. [PubMed: 20377624]

243. Biello SM, Mrosovsky N. Phase response curves to neuropeptide Y in wildtype and tau mutant hamsters. J Biol Rhythms. 1996; 11:27-34. [PubMed: 8695889]

244. Biello SM, et al. Circadian phase shifts to neuropeptide Y In vitro: cellular communication and signal transduction. J Neurosci Off J Soc Neurosci. 1997; 17:8468-8475.

245. Fukuhara C, et al. Neuropeptide Y rapidly reduces Period 1 and Period 2 mRNA levels in the hamster suprachiasmatic nucleus. Neurosci Lett. 2001; 314:119-122. [PubMed: 11704298]

246. Gamble KL, et al. Paradoxical effects of NPY in the suprachiasmatic nucleus. Eur J Neurosci. 2006; 23:2488-2494. [PubMed: 16706855]

247. Besing RC, et al. Neuropeptide Y-induced phase shifts of PER2::LUC rhythms are mediated by long-term suppression of neuronal excitability in a phase-specific manner. Chronobiol Int. 2012; 29:91-102. [PubMed: 22324550]

248. Brothers SP, Wahlestedt C. Therapeutic potential of neuropeptide Y (NPY) receptor ligands. EMBO Mol Med. 2010; 2:429-439. [PubMed: 20972986]

249. Ding JM, et al. Resetting the biological clock: mediation of nocturnal circadian shifts by glutamate and NO. Science. 1994; 266:1713-1717. [PubMed: 7527589]

250. Ding JM, et al. Resetting the Biological Clock: Mediation of Nocturnal CREB Phosphorylation via Light, Glutamate, and Nitric Oxide. J Neurosci. 1997; 17:667-675. [PubMed: 8987789]

251. Agostino PV, et al. Sildenafil accelerates reentrainment of circadian rhythms after advancing light schedules. Proc Natl Acad Sci. 2007; 104:9834-9839. [PubMed: 17519328]

252. Jones KA, et al. Small-molecule antagonists of melanopsin-mediated phototransduction. Nat Chem Biol. 201310.1038/nchembio.1333

253. Siegel JM. The neurobiology of sleep. Semin Neurol. 2009; 29:277-296. [PubMed: 19742406]

254. Saper CB, et al. Sleep state switching. Neuron. 2010; 68:1023-1042. [PubMed: 21172606]

255. Mieda M, Sakurai T. Overview of orexin/hypocretin system. Prog Brain Res. 2012; 198:5-14. [PubMed: 22813966] 
256. Mahlios J, et al. The autoimmune basis of narcolepsy. Curr Opin Neurobiol. 201310.1016/j.conb. 2013.04.013

257. Gotter AL, et al. Orexin receptors as therapeutic drug targets. Prog Brain Res. 2012; 198:163188. [PubMed: 22813974]

258. Uslaner JM, et al. Orexin receptor antagonists differ from standard sleep drugs by promoting sleep at doses that do not disrupt cognition. Sci Transl Med. 2013; 5:179ra44.

259. Mignot E. Physiology. The perfect hypnotic? Science. 2013; 340:36-38. [PubMed: 23559238]

260. Brisbare-Roch C, et al. Promotion of sleep by targeting the orexin system in rats, dogs and humans. Nat Med. 2007; 13:150-155. [PubMed: 17259994]

261. Chen Z, et al. Identification of diverse modulators of central and peripheral circadian clocks by high-throughput chemical screening. Proc Natl Acad Sci U S A. 2012; 109:101-106. [PubMed: 22184224]

262. Hirota T, et al. High-throughput chemical screen identifies a novel potent modulator of cellular circadian rhythms and reveals CKIa as a clock regulatory kinase. PLoS Biol. 2010; 8:e1000559. [PubMed: 21179498]

263. Wittmann M, et al. Social jetlag: misalignment of biological and social time. Chronobiol Int. 2006; 23:497-509. [PubMed: 16687322] 
Circadian dysfunction is a growing concern in our society and interventions are needed

Scheduled light exposure, meals and exercise may strengthen circadian function

Melatonin is among the best-studied circadian modulators available

Promising new drugs may come from re-purposing known agents

New high-throughput screens are identifying novel compounds 




Figure 1.

The molecular clock. The molecular feedback loop is at the core of circadian rhythm generation and drives approximately $24 \mathrm{hr}$ oscillations in core clock protein expression. The loop is composed of a positive arm (CLOCK and BMAL1) that bind to E-box consensus sequences driving the expression of PER and CRY, which are components of the negative arm of the loop. PER and CRY inhibit the ability of CLOCK and BMAL1 to bind onto DNA, thereby leading to the gradual decline of PER and CRY levels allowing CLOCK and BMAL1 to once again restart the positive drive of the loop. Post-translational modifications by Casein Kinase $1 \delta, \varepsilon(\mathrm{CK} 1 \delta, \varepsilon)$ or additional loops (REV-ERB and ROR regulation of Bmall expression) reinforce and fine-tune the clock. Many of these circadian clock genes 
drive the rhythmic expression of other output genes or clock controlled genes (CCGs) that are involved in a variety of cellular processes. 


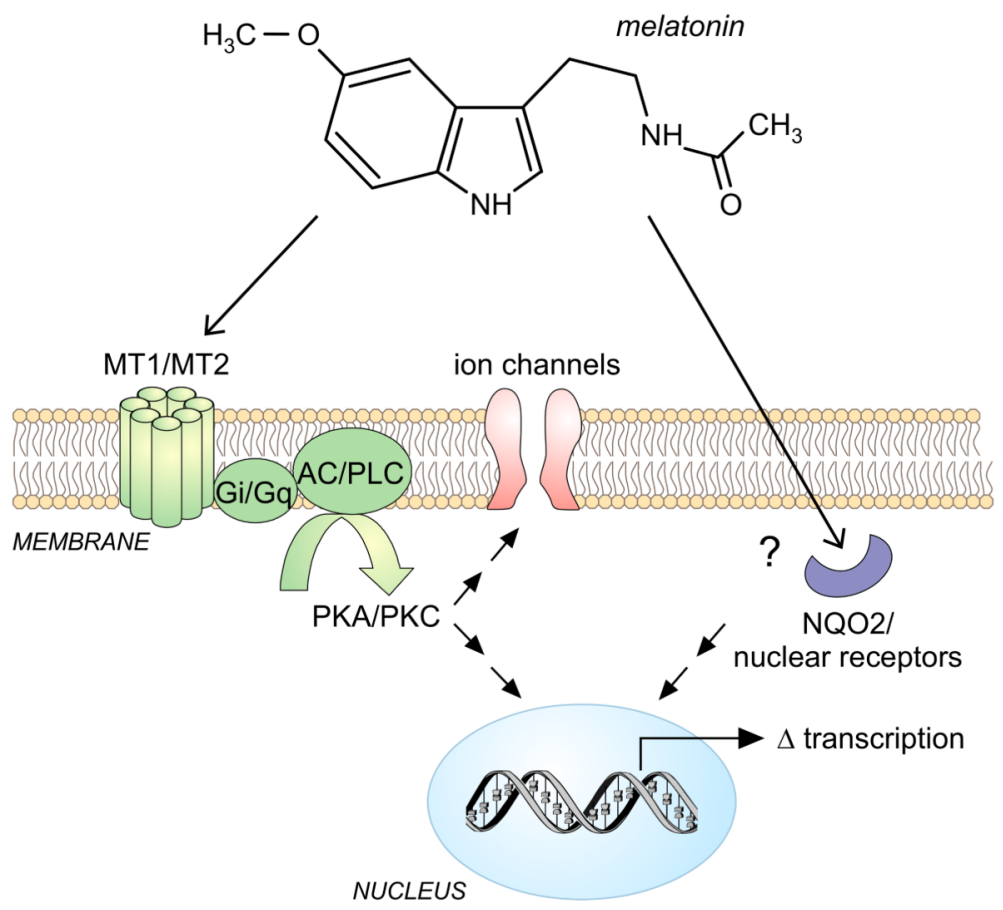

Figure 2.

Melatonin signaling and modulation of the molecular clock. Melatonin is the most-studied pharmacological agent that modulates and benefits the circadian system. Melatonin interactions with the MT1 and MT2 G- $\mathrm{a}_{\mathrm{i}}$ and $\mathrm{G}-\mathrm{a}_{\mathrm{q}}$ protein coupled receptors lead to the inhibition of adenylate cyclase (AC) and Phospholipase $\mathrm{C}$ (PLC) and down regulation of $\mathrm{PKA} / \mathrm{PKC}$ signaling altering ion channel function and changes in circadian-related transcription. Melatonin also binds the enzyme quinone reductase 2 (NQO2) and modulates the function of nuclear receptors although the physiological significance of this binding is not yet clear. 


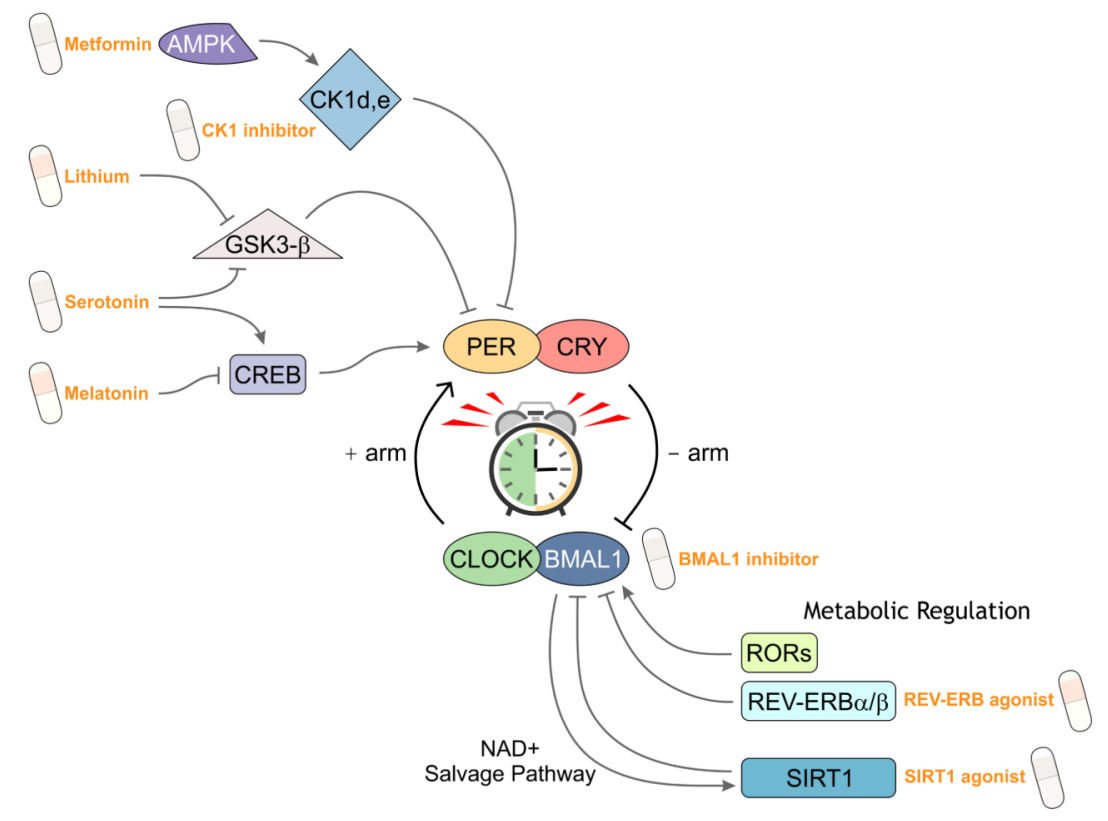

Figure 3.

Drug targets of the molecular clock. Various pathways that modulate the core molecular feedback loop can be targeted by pharmacological agents leading to changes in the amplitude, phase and period of molecular oscillations. Results from ongoing highthroughput screens will expand potential drug-able pathways that could one day lead to medications able to predictably modulate the circadian system. 
Table 1

Pharmacological targeting of the circadian system. List of potential drug targets aimed at modulating various parameters of circadian rhythmicity.

\begin{tabular}{|c|c|c|c|}
\hline Goal & Utility & Possible targets & Citations \\
\hline Enhance central clock & Counter age- or disease-related decline. & VIPR2 agonists; Lithium & 213 \\
\hline Suppress central clock & Useful in anticipation of jet travel or shift work & $\begin{array}{l}\text { Enhanced GABA signaling; } \\
\text { REV-ERBa agonist; } \\
\text { Sirturin } 1 \text { activator; } \\
\text { Chronic melatonin agonists; } \\
\text { Bmal1 suppression }\end{array}$ & $\begin{array}{l}88 \\
234 \\
239\end{array}$ \\
\hline Alter period of molecular clock & Useful to correct for phase advance or phase delay & $\begin{array}{l}\text { Lithium-GSK- } 3 \beta \text { signaling; } \\
\text { Casein kinase signaling; } \\
\text { VIP signaling }\end{array}$ & $\begin{array}{l}213 \\
232,262 \\
188\end{array}$ \\
\hline Alter phase of molecular clock & $\begin{array}{l}\text { Useful to entrain patients without light perception; } \\
\text { non- } 24 \text { hour disorder; } \\
\text { potentially useful to correct for phase advance or } \\
\text { delays. }\end{array}$ & $\begin{array}{l}\text { Phasic melatonin; } \\
\text { Serotonin signaling; } \\
\text { Lithium/Valproic Acid; } \\
\text { NO; } \\
\text { Melanopsin antagonist; } \\
\text { NPY signaling }\end{array}$ & $\begin{array}{l}104,206,207,210 \\
223-226,230 \\
216 \\
249-250 \\
252 \\
242-244,247\end{array}$ \\
\hline Align peripheral clocks & $\begin{array}{l}\text { Counter age- or disease-related decline; } \\
\text { Re-establish rhythms after travel or shift work }\end{array}$ & $\begin{array}{l}\text { Phasic melatonin agonists; } \\
\text { Phasic cortisol analogs; } \\
\text { Phasic NE receptor agonists; } \\
\text { Metformin; } \\
\text { REV-ERBa agonist; } \\
\text { Sirtuin } 1 \text { activator }\end{array}$ & $\begin{array}{l}190,210,212 \\
189 \\
191 \\
218,220 \\
234,236 \\
239\end{array}$ \\
\hline
\end{tabular}

